\title{
Crizotinib, a MET inhibitor, prevents peritoneal dissemination in pancreatic cancer
}

\author{
SOICHI TAKIGUCHI ${ }^{1}$, KAZUKO INOUE ${ }^{1}$, KIMIHIKO MATSUSUE ${ }^{3}$, \\ MASAYUKI FURUKAWA ${ }^{2}$, NORIHIRO TERAMOTO ${ }^{4}$ and HARUO IGUCHI ${ }^{5,6}$
}

\begin{abstract}
${ }^{1}$ Clinical Research Institute, and ${ }^{2}$ Department of Hepato-Biliary-Pancreatology, National Kyushu Cancer Center, Fukuoka 811-1395; ${ }^{3}$ Department of Hygiene Chemistry, Faculty of Pharmaceutical Sciences, Fukuoka University, Fukuoka 814-0180; ${ }^{4}$ Division of Pathology, and ${ }^{5}$ Clinical Research Institute, National Hospital Organization Shikoku Cancer Center, Matsuyama 791-0280; ${ }^{6}$ Sasebo Kyosai Hospital, Sasebo 857-8575, Japan
\end{abstract}

Received January 24, 2017; Accepted April 18, 2017

DOI: 10.3892/ijo.2017.3992

\begin{abstract}
Peritoneal dissemination is a frequent occurrence in pancreatic cancer, which is associated with a poor prognosis. MET is associated with the progression of pancreatic cancer; therefore, we evaluated the effect of a MET inhibitor, crizotinib, on peritoneal dissemination of pancreatic cancer. Crizotinib inhibited the growth of 8 pancreatic cancer cell lines with the $\mathrm{IC}_{50}$ ranging from 1.4 to $4.3 \mu \mathrm{M}$. Invasion of the pancreatic cancer cell line Suit-2, was suppressed in vitro at a concentration of $1.0 \mu \mathrm{M}$, which is sufficient for the inhibition of MET phosphorylation. This effect on cell invasion was also recapitulated by the reduction of MET expression in Suit-2 with siRNA. Crizotinib also inhibited RhoA activation in addition to MET phosphorylation. We further evaluated the effect of crizotinib on peritoneal dissemination of pancreatic cancer in vivo. Crizotinib reduced tumor burden and ascites accumulation due to development of peritoneal dissemination after inoculation of Suit-2. Taken together, crizotinib may be a potent drug for treating peritoneal dissemination of pancreatic cancer by inhibiting cancer cell proliferation and invasion, at least in part through the suppression of HGF/MET signaling and RhoA activation.
\end{abstract}

\section{Introduction}

Pancreatic cancer has no early symptoms and is generally silent until the disease is advanced. During the progression of pancreatic carcinomas, cancer cells frequently released from the surface of the tumor can adhere to and invade tissues and organs in the peritoneal cavity. Patients have a median

Correspondence to: Dr Soichi Takiguchi, Clinical Research Institute, National Kyushu Cancer Center, 3-1-1 Notame, Minami-ku, Fukuoka 811-1395, Japan

E-mail: sctakigu@nk-cc.go.jp

Key words: pancreatic cancer, peritoneal dissemination, cell invasion, crizotinib, hepatocyte growth factor, MET, RhoA survival of 4-8 months after the diagnosis of pancreatic cancer, partly because of the advanced stage of the disease at the time of diagnosis and start of treatment (1-3). Notably, peritoneal dissemination is a frequent occurrence in pancreatic cancer, which is associated with a poor prognosis. It is therefore necessary to discover new therapies or therapeutic combinations that control peritoneal dissemination in order to significantly alter the poor outcome of this deadly disease. The anti-metabolite agent gemcitabine is currently used to treat pancreatic cancer $(4,5)$. While gemcitabine has shown a significant benefit in clinical applications, its ability to treat pancreatic cancer is limited. Furthermore, the more recently approved chemotherapy combinations folic acid, fluorouracil, irinotecan, and oxaliplatin (FOLFIRINOX) and nab-paclitaxel plus gemcitabine only modestly improve survival in advanced pancreatic cancer (6-9). Therefore, new therapeutic approaches need to be investigated to improve the treatment of this deadly neoplasm.

Hepatocyte growth factor (HGF) was originally identified as a liver mitogen and fibroblast-derived epithelial motility factor, and it is the only physiological ligand for the MET receptor tyrosine kinase (RTK) (10). Both levels of HGF and MET are elevated in multiple cancers, including pancreatic ductal adenocarcinoma (PDAC) (11), and are associated with increased tumor cell invasion, distant metastases, and a poor prognosis $(10,12)$. An important process in cancer-cell metastasis is the conversion of epithelial cells to a migratory phenotype, a phenomenon known as epithelial-mesenchymal transition (EMT) $(13,14)$. HGF-induced scattering of Madin-Darby canine kidney cells is a routinely used model of EMT, in which actin cytoskeletal rearrangement is known to be dependent on Rho family GTPases $(15,16)$. A model of HGF-induced EMT has been developed using the human prostate cancer cell line DU145. HGF-induced scattering of DU145 cells was dependent on the activity of Rho family GTPases and on a phosphatidylinositide 3-kinase pathway (17).

Crizotinib is a small-molecule inhibitor that is selective for MET as well as anaplastic lymphoma kinase (ALK) and ROS1 (18-21). It has been shown to inhibit cell proliferation, migration, and invasion of several tumor cell lines in vitro and 
it has also displayed significant antitumor activity in xenograft mouse models (22-24).

In order to elucidate the mechanism of crizotinib on the inhibition of PDAC progression, we evaluated the effect of the drug on cell proliferation and invasion in vitro and peritoneal dissemination in vivo. Our results showed that crizotinib may be a potent drug for treating peritoneal dissemination of PDAC by inhibiting cancer cell proliferation and invasion.

\section{Materials and methods}

Cancer cell lines, animals, and ethics. AsPC-1, BxPC-3, H-48-N, KP-2, KP-3, MIAPaCa-2, Panc-1 and Suit-2 are cell lines that were derived from a human PDAC. AsPC-1, BxPC-3, H-48-N, MIAPaCa-2 and Panc-1 were obtained from American Type Culture Collection (Manassas, VA, USA). KP-2, KP-3 and Suit-2 were obtained from the Japanese Collection of Research Bioresources Cell Bank (Osaka, Japan). The human prostate cancer cell line PC3, non-small cell lung cancer cell line A549 and breast cancer cell line MCF-7 were obtained from American Type Culture Collection. All cell lines were cultured in RPMI-1640 medium (Invitrogen, Carlsbad, CA, USA) supplemented with $10 \%$ FBS and $50 \mathrm{U} / \mathrm{ml}$ penicillin and $50 \mu \mathrm{g} / \mathrm{ml}$ streptomycin in a humidified atmosphere under $5 \% \mathrm{CO}_{2}$ at $37^{\circ} \mathrm{C}$. Male nude mice (BALB/c nu/nu), 8 weeks of age (Clea Japan, Tokyo, Japan) were kept under specific pathogen-free conditions. This study was approved by the Institutional Animal Care and Use Committee (permission no. 26-02) and carried out according to the National Kyushu Cancer Center Animal Experimentation Regulation.

Drug sensitivity test. Human PDAC were seeded into 96-well plates $\left(1.25 \times 10^{3}\right.$ cells $\left./ 50 \mu \mathrm{l}\right)$ and allowed to attach for $24 \mathrm{~h}$. Cells were treated with crizotinib $(0.03-10 \mu \mathrm{M})$ (LCLaboratories, Woburn, MA, USA) for 24, 48 and $72 \mathrm{~h}$ in $100 \mu \mathrm{l}$ medium. At the end of drug exposure, $20 \mu \mathrm{l}$ of 3-(4,5-dimethylthiazol2-yl)-5-(3-carboxymethoxyphenyl)-2-(4-sulfophenyl)-2H-tetrazolium (MTS) reagent (Promega, Madison, WI, USA) was added and cells were incubated in humidified $5 \% \mathrm{CO}_{2}$ atmosphere. After $2 \mathrm{~h}$, spectrophotometric readings were taken for each sample according to the manufacturer's instructions. Cell growth inhibition was expressed as a percentage of the absorbance of control cultures measured at $492 \mathrm{~nm}$ with a microplate reader. The $50 \%$ inhibitory concentration of cell growth $\left(\mathrm{IC}_{50}\right)$ was calculated by a sigmoidal dose-response curve (GraphPad PRISM, San Diego, CA, USA).

Reverse transcription and quantitative real-time polymerase chain reaction $(P C R)$. Reverse transcription was performed using the ThermoScript RT-PCR system (Invitrogen) according to the manufacturer's instructions. Quantitative real-time PCR (qRT-PCR) was performed using the ABI PRISM 7000 Sequence Detection system (Applied Biosystems, Foster City, CA, USA) and SYBR Premix Ex Taq (Takara Bio, Otsu, Shiga, Japan). The human gene-specific primers were 5'-TACAGGG GCACTGTCAATACC-3' and 5'-GGATACTGAGAATCCCA ACGC-3' for HGF, 5'-GCCCTCTGGAAGGTACATTGC-3' and 5'-GAGCACTGTCCAACCATGCTT-3' for ALK, 5'-TGG TGCAGAGGAGCAATGG-3' and 5'-CATTCTGGATGGGT GTTTCCG-3' for MET, 5'-CCACATAATCTGAGTGAACC
GTG-3' and 5'-CGCTGCTACAGCCAACCTC-3' for ROS1, and 5'-CATGTACGTTGCTATCCAGGC-3' and 5'-CTCCTTA ATGTCACGCACGAT-3' for $\beta$-actin.

Immunoblot analysis. Anti-MET, p-MET (Tyr1234/1235), AKT, p-AKT (Ser473), MAPK, and p-MAPK (Tyr202/204) antibodies were obtained from Cell Signaling Technology (Beverly, MA, USA), and anti- $\beta$-actin antibody was obtained from Biovision (Mountain View, CA, USA). Protein samples were separated by sodium dodecyl sulfate-polyacrylamide gel electrophoresis and then transferred to polyvinylidene difluoride membranes (Millipore, Billerica, MA, USA). Following blocking, the membrane was blotted with the appropriate antibody, and subsequently, horseradish peroxidase-conjugated anti-mouse or anti-rabbit IgG (Santa Cruz Biotechnology, Dallas, TX, USA) was applied. The final signal was revealed by ECL chemiluminescence (GE Healthcare Bio-sciences, Pittsburgh, PA, USA). Digital images were analyzed with Image J software to measure the density of each band without a saturated signal.

RNA interference. Silencer Select Pre-designed siRNAs designed to target MET (si-MET), ROS1 (si-ROS1), and ALK (si-ALK), and negative controls designed not to target any known human gene (si-NC) were purchased from Thermo Fisher Scientific (Waltham, MA, USA). For the silencing assay, we transfected $1 \times 10^{6}$ of human PDAC cells with $15 \mu \mathrm{l}$ of stock Silencer Select siRNA duplexes $(5 \mu \mathrm{M})$ using Lipofectamine RNAiMAX solution (Thermo Fisher Scientific) in a 100-mm diameter culture dish. We harvested total RNA from transfected cells $48 \mathrm{~h}$ after transfection to perform gene expression profiling.

Cell invasion assays. Transwell cell invasion was evaluated using a 24-well chemotaxis chamber with membranes with $8-\mu \mathrm{m}$ pores (BD Biosciences, Franklin Lakes, NJ, USA). RNA interference for Suit- 2 cells was done $24 \mathrm{~h}$ before seeding into the upper chambers as needed. Next, Suit-2 cells were incubated in serum-free culture medium with either DMSO (solvent) or crizotinib $(0.1$ or $1 \mu \mathrm{M})$ for $24 \mathrm{~h}$, transferred to the upper chambers $\left(2.5 \times 10^{5}\right.$ cells $\left./ 500 \mu \mathrm{l}\right)$ and allowed to migrate through Matrigel-coated $(8.7 \mathrm{mg} / \mathrm{ml})$ membranes for $24 \mathrm{~h}$. The lower chambers were filled with culture medium containing $10 \% \mathrm{FBS}$, without or with HGF (50 $\mathrm{ng} / \mathrm{ml})$, and with the same concentrations of crizotinib as in the upper chambers. Non-migrated cells were wiped off with a cotton swab, the filter was stained with Diff-Quik stain solution (Siemens, Munich, Germany), and the number of remaining cells was counted under a microscope.

Rho pull-down assay. The Rho pull-down assay was performed using a Rho activation assay kit according to the manufacturer's instructions (Cytoskeleton, Denver, CO, USA). Briefly, cells $\left(3 \times 10^{5} / \mathrm{ml}\right)$ were cultured under serum-free conditions without or with crizotinib $(0.1$ and $1 \mu \mathrm{M})$ for $24 \mathrm{~h}$. After incubation, the cells were stimulated with HGF $(50 \mathrm{ng} / \mathrm{ml})$ for $60 \mathrm{~min}$ and lysed in $\mathrm{Mg}^{2+}$ lysis buffer. Equal volumes of cell lysates were incubated with Rhotekin-RBD beads. Bound RhoA proteins were detected by western blotting using a monoclonal antibody against RhoA. Western blotting of 


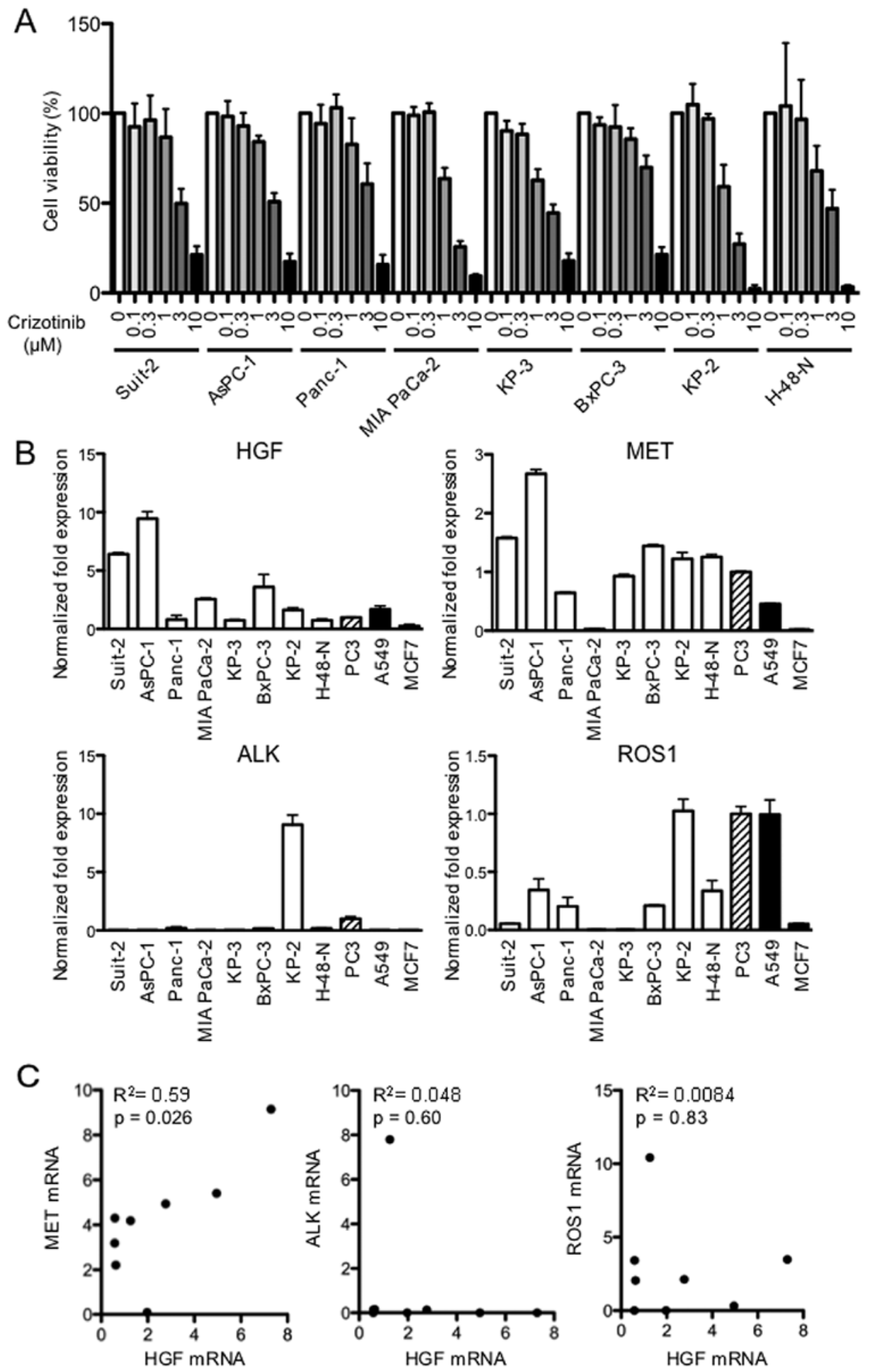

Figure 1. Effect of crizotinib on proliferation and relative expression levels of HGF, MET, ALK and ROS1 in PDAC cells. (A) PDAC cells were plated and treated with increasing doses of crizotinib for $48 \mathrm{~h}$ in 96 -well plates and then cell viability was measured as the percentage of untreated controls ( $\mathrm{n}=6$ ). Crizotinib inhibited cell proliferation in a dose-dependent manner only at higher concentrations. The $\mathrm{IC}_{50}$ range is 1.4-4.3 $\mu \mathrm{M}$. (B) Relative expression levels of HGF, MET, ALK and ROS1 in PDAC cells quantified using qRT-PCR. Each expression level was normalized to $\beta$-actin and compared with the expression levels of human prostatic adenocarcinoma cell line PC3 as a control. (C) The mRNA expression of HGF and MET significantly correlated (Spearman $\mathrm{R}^{2}=0.59$, $\mathrm{P}=0.026$ ).

the total amount of RhoA in cell lysates was performed for comparison with Rho activity (level of GTP-bound Rho) in the same samples.
In vivo peritoneal dissemination model of pancreatic cancer. Five-week-old male nude mice (BALB-cAJcl-nu/nu, Clea Japan) were housed in filtered-air, laminar-flow cabinets 
A

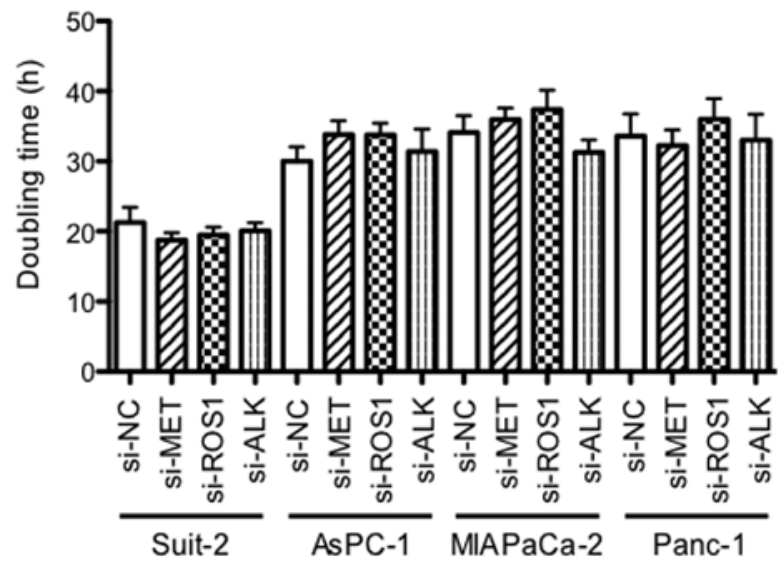

B

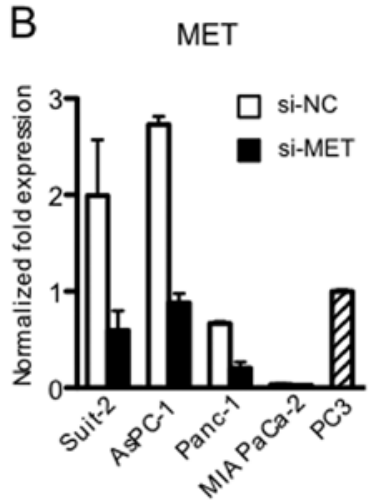

ROS1

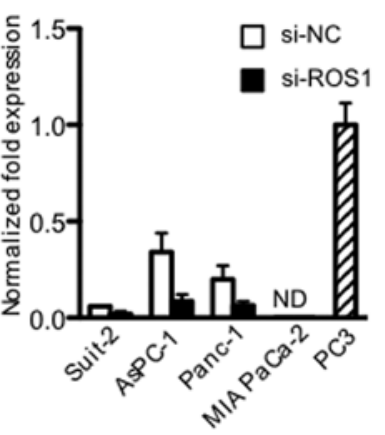

ALK

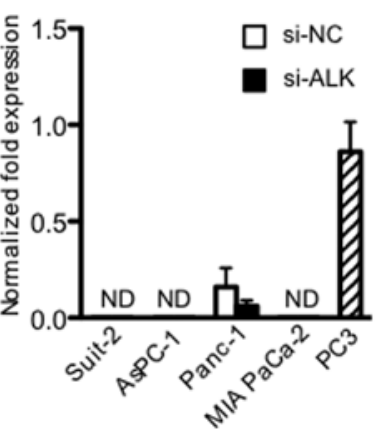

Figure 2. Effects of MET, ROS1 and ALK siRNA knockdown on cell proliferation. (A) PDAC cells were transfected with control, MET, ALK, or ROS1 siRNA. Transfected cells were plated in 96 -well plates $(\mathrm{n}=6)$ and cell viability was measured after 24,48 and $72 \mathrm{~h}$ as the percentage of control siRNA-transfected cells. Doubling time was determined from a least-squares regression fit of cell number versus time during the logarithmic growth phase. (B) Knockdown efficiencies of the MET, ROS1 and ALK siRNA measured at $48 \mathrm{~h}$ after transfection. Each expression level was normalized to $\beta$-actin and compared with the expression levels of human prostatic adenocarcinoma cell line PC3 as a control. ND, not detected.

and were manipulated using aseptic procedures. To prepare the in vivo peritoneal dissemination model, Suit-2 cells were injected i.p. as a cell suspension into nude mice $\left(1 \times 10^{6}\right.$ cells in $200 \mu \mathrm{l}$ PBS per animal). This model using Suit-2 is not only simple and reproducible but also has characteristics that resemble those of human pancreatic cancer. The treatment regimens started on the day of tumor inoculation and continued for 3 weeks. Crizotinib was delivered using a vehicle (sterile saline with $0.5 \%$ methylcellulose suspension) and given by oral gavage every day. The daily dose of crizotinib used was $50 \mathrm{mg} /$ $\mathrm{kg} / \mathrm{d}(18-20)$. At the end of the treatment period, the mice were sacrificed. The volume of ascites was measured and tumor tissue was excised, weighed, fixed in $10 \%$ neutral buffered formalin, and embedded in paraffin. Paraffin sections $(5 \mu \mathrm{m})$ were stained with hematoxylin and eosin. Blood samples were collected from the left heart ventricle and assayed for serum CA19-9.

Statistical analysis. Results are reported as the mean \pm SD of triplicates unless otherwise stated. Group comparisons were performed using one-way analysis of variance (ANOVA) followed by an unpaired Student's t-test. Significantly differentially expressed genes were analyzed by Spearman's rank correlation. Differences between groups were considered statistically significant at $\mathrm{P}<0.05$. Tests were done in triplicates unless otherwise noted.
Table I. Crizotinib inhibition $\left(\mathrm{IC}_{50}\right)$ of the growth of PDAC cells.

\begin{tabular}{lc}
\hline Cell lines & $\mathrm{IC}_{50}(\mu \mathrm{M})$ \\
\hline Suit-2 & $3.4 \pm 0.9$ \\
AsPC-1 & $3.2 \pm 0.3$ \\
Panc-1 & $3.5 \pm 1.0$ \\
MIA PaCa-2 & $1.5 \pm 0.3$ \\
KP-3 & $2.1 \pm 0.5$ \\
BxPC-3 & $4.3 \pm 0.6$ \\
KP-2 & $1.4 \pm 0.5$ \\
H-48-N & $2.1 \pm 0.8$ \\
\hline
\end{tabular}

\section{Results}

Cytotoxic effect of crizotinib on PDAC cells. The effect of crizotinib on PDAC cell growth was examined in vitro using the MTS assay. Treatment with crizotinib (0.1-10 $\mu \mathrm{M})$ resulted in a dose-dependent reduction of cell growth after $48 \mathrm{~h}$ of treatment (Fig. 1A) and the $\mathrm{IC}_{50}$ was calculated to be in the range of $1.4-4.3 \mu \mathrm{M}$ (Table I). Next, we examined the mRNA expression levels of HGF, MET, ALK and ROS1, which are the 


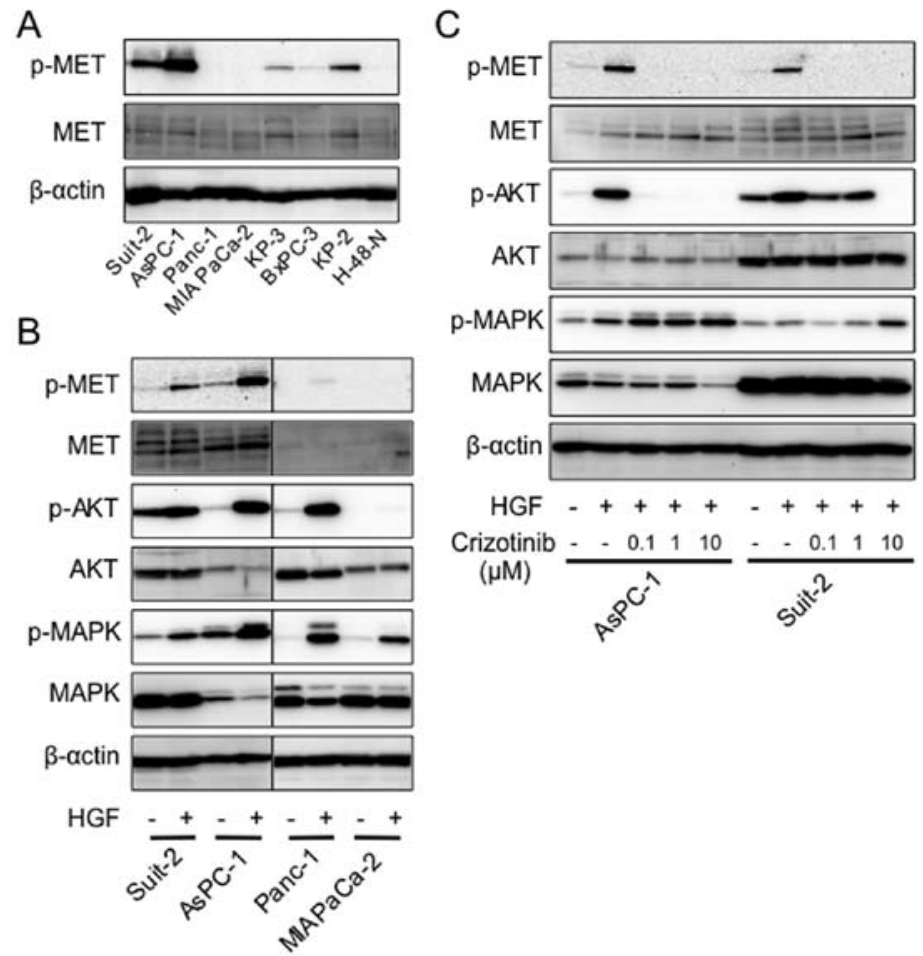

Figure 3. Phosphorylation of the key factors in HGF/MET signaling, and the effect of crizotinib on HGF-induced phosphorylation in PDAC cells. (A) PDAC cells were grown in media supplemented with serum and lysed for immunoblot analysis. (B) PDAC cells were grown in serum-free media for $24 \mathrm{~h}$, incubated with or without $\mathrm{HGF}(20 \mathrm{ng} / \mathrm{ml})$ for $10 \mathrm{~min}$, and lysed for immunoblot analysis. (C) PDAC cells were grown in serum-free media in the absence or presence of crizotinib for $24 \mathrm{~h}$, incubated with or without HGF ( $20 \mathrm{ng} / \mathrm{ml})$ for $10 \mathrm{~min}$, and lysed for immunoblot analysis.

known targets of crizotinib. Most of the PDAC cells expressed substantial levels of HGF and MET mRNA compared with the levels expressed by the human prostate cancer cell line PC3 used as a control cell line (Fig. 1B). Furthermore, the mRNA expression of HGF and MET were positively correlated in the PDAC cells $(\mathrm{P}=0.026)$. However, the mRNA expression of HGF and ALK, or HGF and ROS1 were not correlated in the same PDAC cells (Fig. 1C).

Downregulation of MET, ROS1 and ALK kinases by siRNA does not affect the proliferation of PDAC cell lines. Because dysregulated RTKs induce tumor growth and metastasis, we tested the effect of MET, ROS1 and ALK downregulation on proliferation of the PDAC cells. It was found that the proliferation of four PDAC cell lines, assessed by doubling time, was unchanged by the downregulation of MET, ROS1 and ALK (Fig. 2A). Expression of MET, ROS1 and ALK measured at $48 \mathrm{~h}$ after siRNA transfection was reduced by $70-80 \%$ $(\mathrm{P}<0.05)$ (Fig. 2B).

Phosphorylation of key regulatory factors in HGF/MET signaling in PDAC cells. As a considerable amount of HGF and MET mRNA was expressed in PDAC cells (Fig. 1B), we then examined the phosphorylation of the key regulatory factors in HGF/MET signaling. Phosphorylation of MET was higher in AsPC-1 and Suit-2 than in the other PDAC cell lines under normal culture conditions (Fig. 3A). We next examined whether the phosphorylation of MET was induced by the addition of HGF in PDAC cells. Results showed that phosphorylation was strongly induced in Suit-2 and AsPC-1, slightly induced in Panc-1, and not induced in MIA PaCa-2 (Fig. 3B). We next examined whether HGF-induced phosphorylation of the key regulatory factors in HGF/MET signaling was inhibited by crizotinib in AsPC-1 and Suit-2. Phosphorylation of MET was inhibited at the concentration of $0.1 \mu \mathrm{M}$ in both cell lines, and phosphorylation of AKT was inhibited at $0.1 \mu \mathrm{M}$ and $10 \mu \mathrm{M}$ of crizotinib in AsPC-1 and Suit-2, respectively. However, phosphorylation of MAPK was not inhibited in both cell lines (Fig. 3C).

Importance of HGF/MET signaling in invasion by Suit-2. To assess the effect of crizotinib on cell invasion, Suit- 2 cells were seeded into Matrigel chambers in serum-free culture medium with either DMSO (solvent) or crizotinib $(0.1$ or $1 \mu \mathrm{M})$ and allowed to migrate into the medium in the lower chamber containing $10 \%$ FBS and with the same concentrations of crizotinib as in the upper chambers. It was found that there was no significance between the groups (Fig. 4A, left). However, when medium was supplemented with $50 \mathrm{ng} / \mathrm{ml}$ of HGF in the lower chambers, HGF-induced invasion was completely blocked by $1 \mu \mathrm{M}$ of crizotinib $(\mathrm{P}<0.05)$ (Fig. $4 \mathrm{~A}$, right). Next, to determine which RTK was critical to the HGF-induced invasion, Suit- 2 cells were treated with MET, ROS1 and ALK siRNA, and allowed to migrate into the medium containing FBS in the lower chamber. It was found that there was no significant difference between the groups (Fig. 4B, left). However, when HGF was added to FBS, HGF-induced invasion was not blocked by treatment with NC, ROS1 and ALK siRNAs, while it was completely blocked by treatment with MET siRNA $(\mathrm{P}<0.01)$ (Fig. 4B, right). Expression of MET, 
A

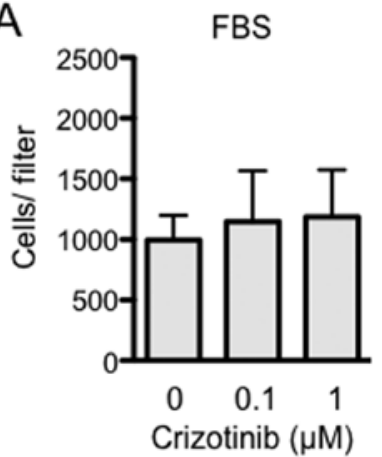

B

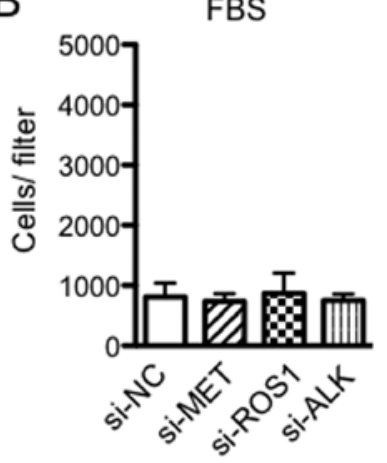

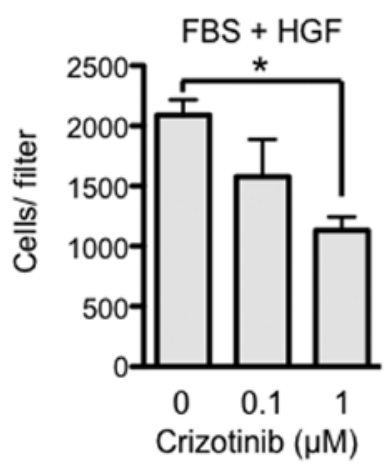

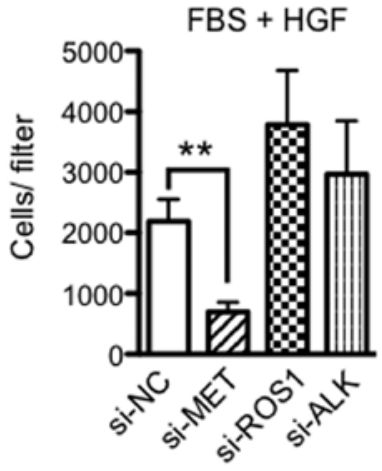

C

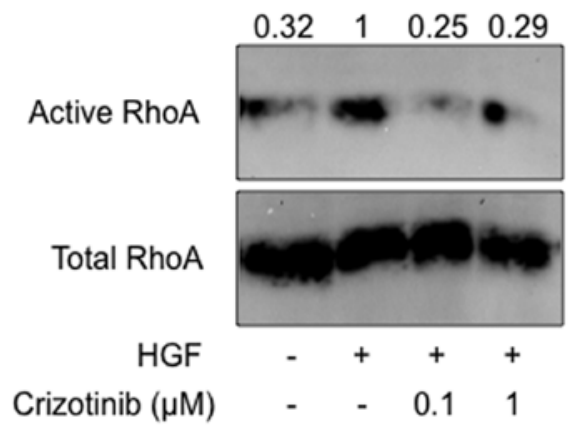

Figure 4. Involvement of HGF/MET signaling in the invasion of Suit-2. (A) Suit-2 cells were seeded into a Matrigel chamber in serum-free media without or with crizotinib $(0.1$ or $1 \mu \mathrm{M})$. Cells were then allowed to migrate for $24 \mathrm{~h}$ into media containing 10\% FBS with or without HGF $(50 \mathrm{ng} / \mathrm{ml})$ in the lower chamber, with the same concentrations of crizotinib as in the upper chambers. The invasion of Suit-2 cells was significantly inhibited when the cells were treated with crizotinib $(1 \mu \mathrm{M})$ and migrated into media containing $10 \%$ FBS with HGF $(50 \mathrm{ng} / \mathrm{ml})$. ${ }^{*} \mathrm{P}<0.05$. (B) Suit- 2 cells were transfected with negative control (NC), MET, ROS1 or ALK siRNA, seeded into Matrigel chambers, and allowed to migrate for $24 \mathrm{~h}$ into media containing 10\% FBS with or without HGF $(50 \mathrm{ng} / \mathrm{ml})$ in the lower chamber. Knockdown of MET by siRNA inhibited cell migration when cells were allowed to migrate into media containing $10 \%$ FBS with HGF $(50 \mathrm{ng} / \mathrm{ml})$. ${ }^{* *} \mathrm{P}<0.01$. (C) Suit- 2 cells were incubated under serum-free condition with or without crizotinib for $24 \mathrm{~h}$. After incubation, the cells were stimulated with HGF $(50 \mathrm{ng} / \mathrm{ml})$ for $1 \mathrm{~h}$, lysed and incubated with Rhotekin-RBD beads for immunoblot analysis. Bound RhoA proteins were detected by immunoblot analysis using monoclonal antibody against RhoA (upper panel). Immunoblot analysis of the total amount of RhoA in cell lysates (lower panel) was performed for comparison with the Rho activity (level of GTP-bound RhoA) in the same lysates. Relative amounts of active RhoA normalized with the amounts of total RhoA were determined by densitometric scanning and shown in the figure.

ROS1 and ALK measured at $48 \mathrm{~h}$ after siRNA transfection was reduced by $70-80 \%(\mathrm{P}<0.05$, data not shown). Next, to evaluate whether HGF induces RhoA activity in Suit-2 cells, we used a pull-down assay with the fusion protein GST-Rhotekin-RBD,

which recognizes only RhoA-GTP, the active form of RhoA. An increase in RhoA-GTP was observed in Suit-2 treated for $1 \mathrm{~h}$ with HGF (50 ng/ml). Furthermore, the activation of RhoA was suppressed by the addition of crizotinib $(0.1$ or $1 \mu \mathrm{M})$ (Fig. 4C).

Crizotinib inhibits the peritoneal dissemination of Suit-2 cells. To examine the effect of crizotinib on peritoneal dissemination in vivo, we used a pancreatic cancer model with i.p. carcinomatosis in nude mice. We started the administration of crizotinib on the day of inoculation of cancer cells. Preliminary experiments revealed that tumor-bearing mice began to exhibit abdominal swelling with ascites $\sim 2.5$ weeks after the inoculation of cancer cells and died with cachexia after the fifth week without any treatment. Therefore, we sacrificed and examined the mice 3 weeks after the inoculation of cancer cells. Fig. 5A shows the effects of crizotinib treatment on ascites formation. The mean volume of ascites was significantly reduced (by $\sim 60 \%$ ) in the group given $50 \mathrm{mg} / \mathrm{kg} / \mathrm{d}$ compared with the untreated group $(1.2 \pm 1.7$ vs. $3.3 \pm 1.0 \mathrm{ml} ; \mathrm{P}<0.01)$. The mean tumor weight on the peritoneum was significantly reduced (by $30 \%$ ) in the treatment group given $50 \mathrm{mg} / \mathrm{kg} / \mathrm{d}$ compared with the untreated group $(0.67 \pm 0.22$ vs. $0.91 \pm 0.19 \mathrm{~g} ; \mathrm{P}<0.05)$ (Fig. 5B). The concentration of CA19-9, which is expressed by Suit-2, was examined in the sera collected from the left heart ventricle (Fig. 5C). The mean concentration of CA19-9 was significantly reduced (by $\sim 85 \%$ ) in the group given $50 \mathrm{mg} / \mathrm{kg} / \mathrm{d}$ of crizotinib compared with the untreated group (4.0 \pm 6.1 vs. $27.3 \pm 23.3 \mathrm{U} / \mathrm{ml} ; \mathrm{P}<0.05)$. At autopsy examination, tumors were found on the surface of the peritoneum, diaphragm, intestines, liver, spleen, pancreas, and kidney, with massive ascites in the control group. Histological appearance of the tumor nests that formed after dissemination of tumor cells in the peritoneum (Fig. 5D) and to the pancreas (Fig. 5F) and liver (Fig. 5G) from the untreated group showed how the tumor extensively invaded the peritoneum.

\section{Discussion}

Peritoneal dissemination frequently occurs in pancreatic cancer, which is associated with a poor prognosis (1-3). MET is associated with the progression of pancreatic cancer (10-12); therefore, we evaluated the effect of the MET inhibitor, crizotinib, on peritoneal dissemination of pancreatic cancer. Crizotinib inhibited the growth of 8 pancreatic cancer cell lines with the $\mathrm{IC}_{50}$ ranging from 1.4 to $4.3 \mu \mathrm{M}$. Invasion of a pancreatic cancer cell line, Suit-2, was suppressed in vitro at a concentration of $1.0 \mu \mathrm{M}$, which is sufficient for the inhibition of MET phosphorylation. This effect on cell invasion was also recapitulated by the reduction of MET expression in Suit-2 with siRNA. Crizotinib also inhibited RhoA activation in addition to MET phosphorylation. We further evaluated the effect of crizotinib on peritoneal dissemination of pancreatic cancer in vivo. Crizotinib reduced tumor burden and ascites accumulation due to peritoneal dissemination after inoculation of Suit-2.

The effect of crizotinib on PDAC cell proliferation was evaluated in vitro. The $\mathrm{IC}_{50}$ values were calculated to be in the range of 1.4-4.3 $\mu \mathrm{M}$, which was comparable to the $\mathrm{IC}_{50}$ values of uveal melanoma cells in the range of $0.75-2 \mu \mathrm{M}(24), \mathrm{IC}_{50}$ 

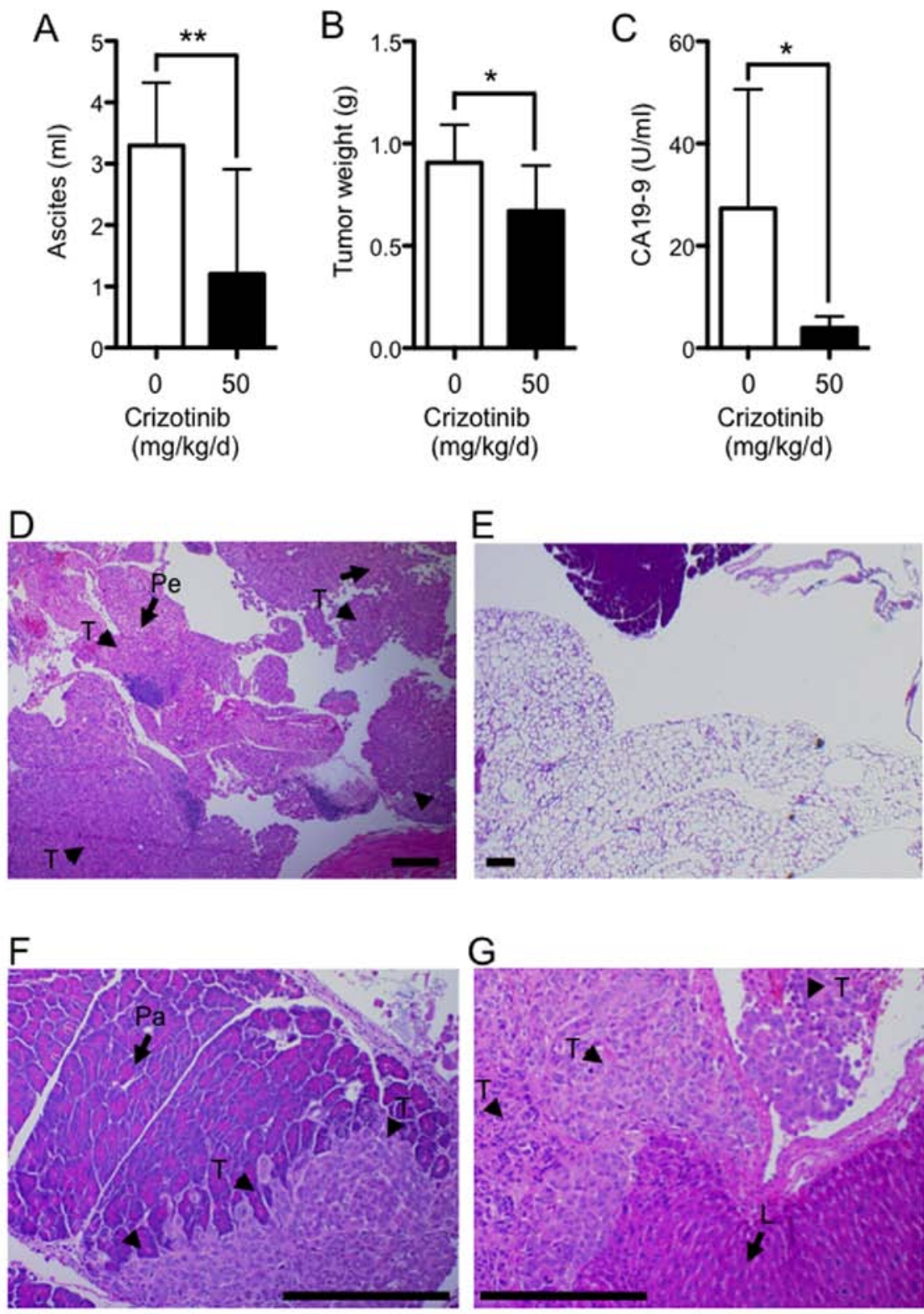

Figure 5. Crizotinib inhibits peritoneal dissemination of Suit-2. Suit-2 cell suspension ( $1 \times 10^{6} / 200 \mu 1 /$ mouse) was injected i.p. into nude mice and treated with crizotinib $(50 \mathrm{mg} / \mathrm{kg}$ ) daily. The mice were sacrificed at 21 days after implantation, and ascites, peritonea and blood sera were collected. The volume of ascites (A), weight of tumor that had disseminated on peritonea (B) and the concentrations of CA19-9 (C) were measured $(\mathrm{n}=8)$. ${ }^{* *} \mathrm{P}<0.01$, ${ }^{*} \mathrm{P}<0.05$. Histologic appearance of disseminated tumor nests in the peritoneum (D), pancreas (F) and liver (G) of Suit-2-implanted nude mouse and peritoneum (E) of mouse treated with crizotinib. Nude mice were sacrificed at 21 days after i.p. injection of Suit-2 cells. Collected tissues were fixed, sectioned, and stained with hematoxylin and eosin. T, tumor nest (arrowhead); Pe, peritoneum (arrow); Pa, pancreas (arrow); L, liver (arrow); bar, $200 \mu \mathrm{m}$ in D-F; $800 \mu \mathrm{m}$ in G.

values of thyroid cancer cells in the range of $2-3.5 \mu \mathrm{M}, \mathrm{IC}_{50}$ value of MDA-MB-231 breast cancer cell $(2.8 \mu \mathrm{M})$, and the $\mathrm{IC}_{50}$ value of HT-29 colon cancer cell $(2.6 \mu \mathrm{M})(25)$. MET-negative MDA-MB-435 melanoma cells had a minimal response to crizotinib, not reaching the $\mathrm{IC}_{50}$ value even in the presence of the maximal drug dose $(10 \mu \mathrm{M})(25)$. We then examined the relationship between the expression of MET, ROS1 and ALK and the effect of crizotinib on PDAC cell proliferation. To do this, we chose highly MET-expressing Suit-2 and AsPC-1, and marginally MET-expressing Panc-1 and MIA $\mathrm{PaCa}-2$, as these 4 PDAC cell lines showed similar $\mathrm{IC}_{50}$ values. While expression of each RTK was downregulated by siRNA, the doubling time of each cell line was not changed in any of the cases, suggesting that the cell proliferation of PDAC cells was not controlled through only one of the three RTKs targeted by crizotinib. At this point, since no specific ligand for ALK or ROS1 has been found, it is impossible to conduct an experiment to observe the effect of adding ligand to PDAC cells expressing ALK or ROS1. If a specific ligand for them is found in the future, it will lead to more accurate prediction of the efficacy of crizotinib. However, it may actually be difficult as it could vary depending on a variety of factors related to the drug resistance mechanism of cancer cells.

To examine which signaling factors were activated by the addition of HGF to PDAC cells, phosphorylation of MET, AKT and MAPK was examined in the highly MET-expressing 
Suit-2 and AsPC-1, and marginally MET-expressing Panc-1 and MIA PaCa-2. The phosphorylation of MET, AKT and MAPK after the addition of HGF was considerably induced in Suit-2 and AsPC-1. However, the phosphorylation of MET after the addition of HGF was slightly or not induced in Panc-1 or MIA PaCa-2, respectively. However, the phosphorylation of AKT was considerably or slightly induced in Panc-1 or MIA $\mathrm{PaCa}-2$, respectively, and the phosphorylation of MAPK was considerably induced in both cells. These data suggest that the phosphorylation of AKT and MAPK may be induced through non-MET signaling in marginally MET-expressing PDAC cells. Next, blocking of HGF-induced phosphorylation of MET, AKT and MAPK by crizotinib was examined in the highly MET-expressing Suit-2 and AsPC-1. The phosphorylation of MET was blocked at a dose of $0.1 \mu \mathrm{M}$ of crizotinib in both cells, and the phosphorylation of AKT were blocked at $0.1 \mu \mathrm{M}$ and $10 \mu \mathrm{M}$ of crizotinib in Suit-2 and AsPC-1, respectively. The phosphorylation of MAPK was not blocked in either cell even at the maximal drug dose $(10 \mu \mathrm{M})$ of crizotinib, suggesting that the cell proliferation of highly MET-expressing PDAC cells is controlled through HGF/MET/AKT rather than HGF/ MET/MAPK signaling. Taken together, our data suggest that crizotinib inhibits the cell proliferation of PDAC cells, regardless of MET expression and phosphorylation.

To explore the mechanism that controls the peritoneal dissemination of PDAC cells, the effects of crizotinib and downregulation of MET, ROS1 and ALK on the invasion of highly MET-expressing Suit-2 were evaluated in vitro. Based on the results, crizotinib was considered to inhibit the invasion of Suit-2 induced by HGF/MET signaling. We then attempted to identify key regulatory factors in HGF/MET signaling involved in the invasion of Suit- 2 cells. Since it is now well established that invasion of cancer cells is induced by Ras-related GTPases (especially RhoA) (12), the activation of RhoA by the addition of HGF in Suit- 2 was examined by a pull-down assay with the fusion protein GST-Rhotekin-RBD. Indeed, an increase in RhoA-GTP, the active form of RhoA, was observed in Suit-2 cells that were treated for $1 \mathrm{~h}$ with HGF (50 ng/ml). Moreover, the activation of RhoA by HGF was suppressed by the addition of crizotinib $(0.1 \mu \mathrm{M})$. Therefore, the invasion of Suit-2 induced by HGF might be mediated by the activation of RhoA and could be targeted by crizotinib. Furthermore, to examine the effect of crizotinib on peritoneal dissemination in vivo, we used a pancreatic cancer model with i.p. carcinomatosis in nude mice. It was found that the volume of ascites, the tumor weight on peritonea, and the concentration of CA19-9 in the untreated group were significantly reduced in the group given $50 \mathrm{mg} / \mathrm{kg} / \mathrm{d}$ of crizotinib. Taken together, crizotinib may be a potent drug for treating peritoneal dissemination of pancreatic cancer, possibly by inhibiting cancer cell invasion through the inhibition of the HGF/MET signaling and the activation of RhoA.

Several reports on the contribution of HGF/MET signaling to proliferation, motility or metastasis of PDAC cells were published $(26,27)$. Treatment with the combination of crizotinib and gemcitabine was shown to synergistically reduce tumor growth and metastases in orthotopic PDAC models. In one report, crizotinib was shown to inhibit metabolic inactivation of gemcitabine in MET-driven pancreatic carcinoma (26). P21-activated kinase 1 (PAK1) was shown to be a central node in PDAC cells, downstream of multiple growth factor signaling pathways, including $\mathrm{HGF} / \mathrm{MET}$ signaling. PAK1 inhibition blocks signaling to cytoskeletal effectors and tumor cell motility driven by HGF/MET signaling. Inhibition of PAK1 attenuated in vivo tumor growth and metastasis in a model of pancreatic adenocarcinoma (27). In accordance with previous studies, our results indicate that the phosphorylation of MET, AKT and MAPK by the addition of HGF was considerably induced in highly MET-expressing PDAC cells. However, the presence of non-MET-expressing PDAC cells urges us to investigate the contribution of non-MET signaling in PDAC cell proliferation or metastasis.

The following conclusions were drawn from the present study. First, crizotinib has a potent inhibitory effect on the proliferation of PDAC cells, and the effect might not be mediated through one of the three known RTKs targeted by crizotinib. Furthermore, the inhibitory effect was largely unaffected by the status of MET expression and phosphorylation of each PDAC cell line. Second, crizotinib has a potent inhibitory effect on the invasion of highly MET-expressing PDAC cells through the inhibition of HGF/MET signaling and RhoA activation. Finally, crizotinib might be a potent drug for treating peritoneal dissemination of highly MET-expressing pancreatic cancer, possibly by inhibiting cancer cell proliferation and invasion.

\section{Acknowledgements}

This study was supported in part by the Grant-in-Aid for Cancer Research (project no. 00054) from the Ministry of Health, Labour, and Welfare of Japan (H.I.) and Grant-in-Aid for Scientific Research (project no. 25462356) from Japan Society for the Promotion of Science (S.T.).

\section{References}

1. Kleeff J, Michalski C, Friess H and Büchler MW: Pancreatic cancer: From bench to 5-year survival. Pancreas 33: 111-118, 2006

2. Hidalgo M: Pancreatic cancer. N Engl J Med 362: 1605-1617, 2010.

3. Ryan DP, Hong TS and Bardeesy N: Pancreatic adenocarcinoma. N Engl J Med 371: 1039-1049, 2014.

4. Li D, Xie K, Wolff R and Abbruzzese JL: Pancreatic cancer. Lancet 363: 1049-1057, 2004.

5. Ueno H, Kiyosawa K and Kaniwa N: Pharmacogenomics of gemcitabine: Can genetic studies lead to tailor-made therapy? $\mathrm{Br}$ J Cancer 97: 145-151, 2007.

6. Conroy T, Desseigne F, Ychou M, Bouché O, Guimbaud R, Bécouarn Y, Adenis A, Raoul JL, Gourgou-Bourgade S, de la Fouchardière C, et al; Groupe Tumeurs Digestives of Unicancer; PRODIGE Intergroup: FOLFIRINOX versus gemcitabine for metastatic pancreatic cancer. N Engl J Med 364: 1817-1825, 2011.

7. Von Hoff DD, Ervin T, Arena FP, Chiorean EG, Infante J, Moore M, Seay T, Tjulandin SA, Ma WW, Saleh MN, et al: Increased survival in pancreatic cancer with nab-paclitaxel plus gemcitabine. N Engl J Med 369: 1691-1703, 2013.

8. Von Hoff DD, Goldstein D and Renschler MF: Albumin-bound paclitaxel plus gemcitabine in pancreatic cancer. N Engl J Med 370: 479-480, 2014.

9. Suker M, Beumer BR, Sadot E, Marthey L, Faris JE, Mellon EA, El-Rayes BF, Wang-Gillam A, Lacy J, Hosein PJ, et al: FOLFIRINOX for locally advanced pancreatic cancer: A systematic review and patient-level meta-analysis. Lancet Oncol 17: 801-810, 2016.

10. Gherardi E, Birchmeier W, Birchmeier C and Vande Woude G Targeting MET in cancer: Rationale and progress. Nat Rev Cancer 12: 89-103, 2012. 
11. Di Renzo MF, Poulsom R, Olivero M, Comoglio PM and Lemoine NR: Expression of the Met/hepatocyte growth factor receptor in human pancreatic cancer. Cancer Res 55: 1129-1138, 1995.

12. Birchmeier C, Birchmeier W, Gherardi E and Vande Woude GF: Met, metastasis, motility and more. Nat Rev Mol Cell Biol 4: 915-925, 2003.

13. Kang Y and Massagué J: Epithelial-mesenchymal transitions: Twist in development and metastasis. Cell 118: 277-279, 2004.

14. Kalluri R and Weinberg RA: The basics of epithelial-mesenchymal transition. J Clin Invest 119: 1420-1428, 2009.

15. Gherardi E and Stoker M: Hepatocyte growth factor - scatter factor: Mitogen, motogen, and met. Cancer Cells 3: 227-232, 1991.

16. Ridley AJ, Comoglio PM and Hall A: Regulation of scatter factor/hepatocyte growth factor responses by Ras, Rac, and Rho in MDCK cells. Mol Cell Biol 15: 1110-1122, 1995.

17. Wells CM, Ahmed T, Masters JR and Jones GE: Rho family GTPases are activated during HGF-stimulated prostate cancercell scattering. Cell Motil Cytoskeleton 62: 180-194, 2005.

18. Zou HY, Li Q, Lee JH, Arango ME, McDonnell SR, Yamazaki S, Koudriakova TB, Alton G, Cui JJ, Kung PP, et al: An orally available small-molecule inhibitor of c-Met, PF-2341066, exhibits cytoreductive antitumor efficacy through antiproliferative and antiangiogenic mechanisms. Cancer Res 67: 4408-4417, 2007.

19. Christensen JG, Zou HY, Arango ME, Li Q, Lee JH, McDonnell SR, Yamazaki S, Alton GR, Mroczkowski B and Los G: Cytoreductive antitumor activity of PF-2341066, a novel inhibitor of anaplastic lymphoma kinase and c-Met, in experimental models of anaplastic large-cell lymphoma. Mol Cancer Ther 6: 3314-3322, 2007.

20. Yamazaki S, Skaptason J, Romero D, Lee JH, Zou HY, Christensen JG, Koup JR, Smith BJ and Koudriakova T: Pharmacokinetic-pharmacodynamic modeling of biomarker response and tumor growth inhibition to an orally available cMet kinase inhibitor in human tumor xenograft mouse models. Drug Metab Dispos 36: 1267-1274, 2008.
21. Timofeevski SL, McTigue MA, Ryan K, Cui J, Zou HY, Zhu JX, Chau F, Alton G, Karlicek S, Christensen JG, et al: Enzymatic characterization of c-Met receptor tyrosine kinase oncogenic mutants and kinetic studies with aminopyridine and triazolopyrazine inhibitors. Biochemistry 48: 5339-5349, 2009.

22. Sennino B, Ishiguro-Oonuma T, Wei Y, Naylor RM, Williamson CW, Bhagwandin V, Tabruyn SP, You WK, Chapman HA, Christensen JG, et al: Suppression of tumor invasion and metastasis by concurrent inhibition of c-Met and VEGF signaling in pancreatic neuroendocrine tumors. Cancer Discov 2: 270-287, 2012.

23. Zheng X, He K, Zhang L and Yu J: Crizotinib induces PUMAdependent apoptosis in colon cancer cells. Mol Cancer Ther 12: 777-786, 2013.

24. Surriga O, Rajasekhar VK, Ambrosini G, Dogan Y, Huang R and Schwartz GK: Crizotinib, a c-Met inhibitor, prevents metastasis in a metastatic uveal melanoma model. Mol Cancer Ther 12: 2817-2826, 2013

25. Zhou Y, Zhao C, Gery S, Braunstein GD, Okamoto R, Alvarez R, Miles SA, Doan NB, Said JW, Gu J, et al: Off-target effects of c-MET inhibitors on thyroid cancer cells. Mol Cancer Ther 13: 134-143, 2014.

26. Avan A, Caretti V, Funel N, Galvani E, Maftouh M,Honeywell RJ, Lagerweij T, Van Tellingen O, Campani D, Fuchs D, et al: Crizotinib inhibits metabolic inactivation of gemcitabine in c-Met-driven pancreatic carcinoma. Cancer Res 73: 6745-6756, 2013.

27. Zhou W, Jubb AM, Lyle K, Xiao Q, Ong CC, Desai R, Fu L, Gnad F, Song Q, Haverty PM, et al: PAK1 mediates pancreatic cancer cell migration and resistance to MET inhibition. J Pathol 234: 502-513, 2014. 